\title{
Research on Intensive Development Mode of Rural Logistics Network in Hubei that Boosts Agricultural E-commerce
}

\author{
Ying Tan \\ School of Management, Wuhan Donghu College, Wuhan, Hubei, China \\ 85066405@qq.com
}

Key words: Agricultural e-commerce, rural logistics network, intensiveness, development mode

Abstract. According to theories of intensive management and synergistic effect and advanced experience from developed countries like the US and Japan, the paper proposes to build the two-way circulation mode of "third-party logistics + postal logistics", the "farming-school, farming-supermarket and farming-enterprise" connecting mode and the two-way circulation mode of "the leading enterprises in the agricultural industrialization + farmer" that fit in with circumstances of Hubei province, and then illustrates the intensive operation mechanism of the three modes that are "one point with multiple functions, one network with multiple purposes ", thus offering theoretical basis and support for developing Agricultural e-commerce and building intensive rural logistics network in other parts of China.

\section{Introduction}

As e-commerce has become a key driver for rural logistics development, the latter in turn has become an important platform and support for Agricultural e-commerce. Both of them work together to create new economic growth point, but they are mutually influenced and restricted due to an absence of mature market regulations and coordination mechanism. This research, on the premise of securing respective interests of Agricultural e-commerce and rural logistics, draws lessons from the advanced mode of collaborative construction of Agricultural e-commerce and rural logistics in developed countries like the US and Japan, explores actively intensive development mode of rural logistics network that suits Hubei province and boosts its Agricultural e-commerce.

\section{Research Status Review}

Researches on rural logistics in Hubei focus on two directions: one is systematic project. For example, Chen Feng (2010) holds that agricultural logistics development is a systematic project and requires multi-party involvement and cooperation. Wang Lihong (2009) thinks developing agricultural green logistics in Hubei is a systematic project and requires all-round improvement in terms of perspectives, policies and regulations, technology, talents and logistics operation. The other is farm product logistics. Tao Juncheng (2005) maintains that promoting the standardized management of aquatic product "green logistics" is a top priority for sustainable development of aquatic products in Hubei. Duan Lijie (2013) analyzes the development situation of farm product logistics in Hubei and establishes the dynamics model for farm product logistics system of Hubei in the context of e-commerce based on existing problems facing farm product logistics mode in Hubei.

Current research on the relationship between e-commerce and logistics mainly concentrates on the constraints logistics industry development presents to e-commerce growth. For instance, Hu Yunbin, Zhang Fan, Liu Chuanlong and Song Luping (2013) hold that logistics is a basic component of e-commerce, and they complement yet influence each other. Bie Daoxue, Ma Haoying and Bai Jing (2013) analyze the correlation between e-commerce and modern logistics, maintaining that the imbalance between logistics and e-commerce demand hinders joint development of both in China, and they come up with suggestions about logistics resource integration. Ma Jun (2014) opines that Chinese logistics industry development lags behind e-commerce growth rate, and inadequate cooperation between the two leads to a lack of well-developed modern service system.

As the above-mentioned research findings show, current researches on rural logistics development in Hubei done by Chinese scholars tend to focus on analyzing development situation 
and constraints of rural logistics in Hubei while the researches on the correlation between ecommerce and logistics primarily deal with the constraints logistics industry development presents to e-commerce growth. Presently, only a few researches put forward effective measures of rural logistics network development to spur the growth of regional Agricultural e-commerce; moreover, almost no research on the construction of intensive and highly-efficient rural logistics network is done. Therefore, it is of great theoretical and practical significance to study intensive development mode of rural logistics network in Hubei that aims to surmount the bottlenecks of Agricultural e-commerce development and boost its growth based on the development situation of Agricultural e-commerce and rural logistics in Hubei province.

\section{Feasibility study on intensive development of rural logistics network in Hubei that boosts Agricultural e-commerce}

\subsection{Theoretical feasibility}

Synergistic effect refers to a combined or united effect arising from the collaboration between two or more sub-systems in a complicated whole system that produces an effect greater than the simple sum of their individual effects. In other words, it is " $1+1>2$ " . The collaboration between Agricultural e-commerce and rural logistics in Hubei will put an end to the outdated development mode underscoring self-accumulation and low level of interdependence and produce greater combined benefits than individual ones through creating the platform focusing on resource sharing and complementary advantages. E-commerce enterprises and logistics operators should follow the theory of synergy and pursue lower cost and intensive development by integrating resources for logistics business.

\subsection{Practical feasibility}

The collaborative construction of Agricultural e-commerce and rural logistics network in Hubei will accelerate the integration of dual economy of "industry + agriculture" characterized by the two-way circulation mode of agricultural materials and consumer goods going to the countryside and farm products going to cities, greatly facilitate urban-rural integration and solve the problems of "first-mile logistics" for farm products and "last-mile logistics" for industrial products. According to the collaborative development mode, an integration of each factor will promote intensive development of two-way circulation, bring into play the "one point with multiple functions, one network with multiple purposes " effect and lower transaction cost arising from simpler circulation process.

\section{Advanced experience learned for collaborative development of Agricultural e-commerce and rural logistics}

4.1 The US' s two-way circulation mode of online suppliers--farmer cooperatives--farmers American agricultural production is chiefly done by family farms. It has formed a well-established farmer cooperative system after the passage of nearly 200 years. Farmer cooperatives serve as a pivotal logistics node in Agricultural e-commerce. Online suppliers transport to farmer cooperatives goods (including agricultural means of production and consumer goods) ordered by farmers via mature third-party logistics and then farmer cooperatives distribute them to farmers. On the other hand, farmer cooperatives are responsible for purchasing, transporting, processing, packaging and selling farm products, and some cooperatives open online stores and have their own distribution \& logistics systems while others sign sales and purchase contracts with online suppliers and distribute farm products to towns and cities via third-party logistics.

\subsection{Japan' s two-way circulation mode of "agricultural byproducts and production means"} The two-way circulation mode of "agricultural byproducts and production means" refers to the agricultural byproduct circulation mode of farmers--cooperative marketing organization (online suppliers) of farmer association, and production means circulation mode of online suppliers-cooperative purchase organization of farmer association--farmers. 
Japan' s Agricultural e-commerce and logistics mainly rely on farmer association. Functionally, farmer association is divided into cooperative purchase organization and cooperative marketing organization; Japanese farmers get means of production from the cooperative purchase organization while their agricultural byproducts are sold to consumers by the cooperative marketing organization.

\section{Research on intensive development mode of rural logistics network in Hubei that boosts Agricultural e-commerce}

This research concerns four types of logistics of collaborative construction system of Agricultural e-commerce and rural logistics network in Hubei, comments and draws lessons from the advanced experience from developed countries like the US and Japan, builds intensive development mode of rural logistics network in Hubei that boosts Agricultural e-commerce development so as to provide decision-making basis for each level of government, competent departments of agriculture and agricultural business entities.

\subsection{Two-way circulation mode of "third-party logistics + postal logistics"}

\subsubsection{Circulation mode}

(1) Circulation mode of agricultural materials and rural consumer goods

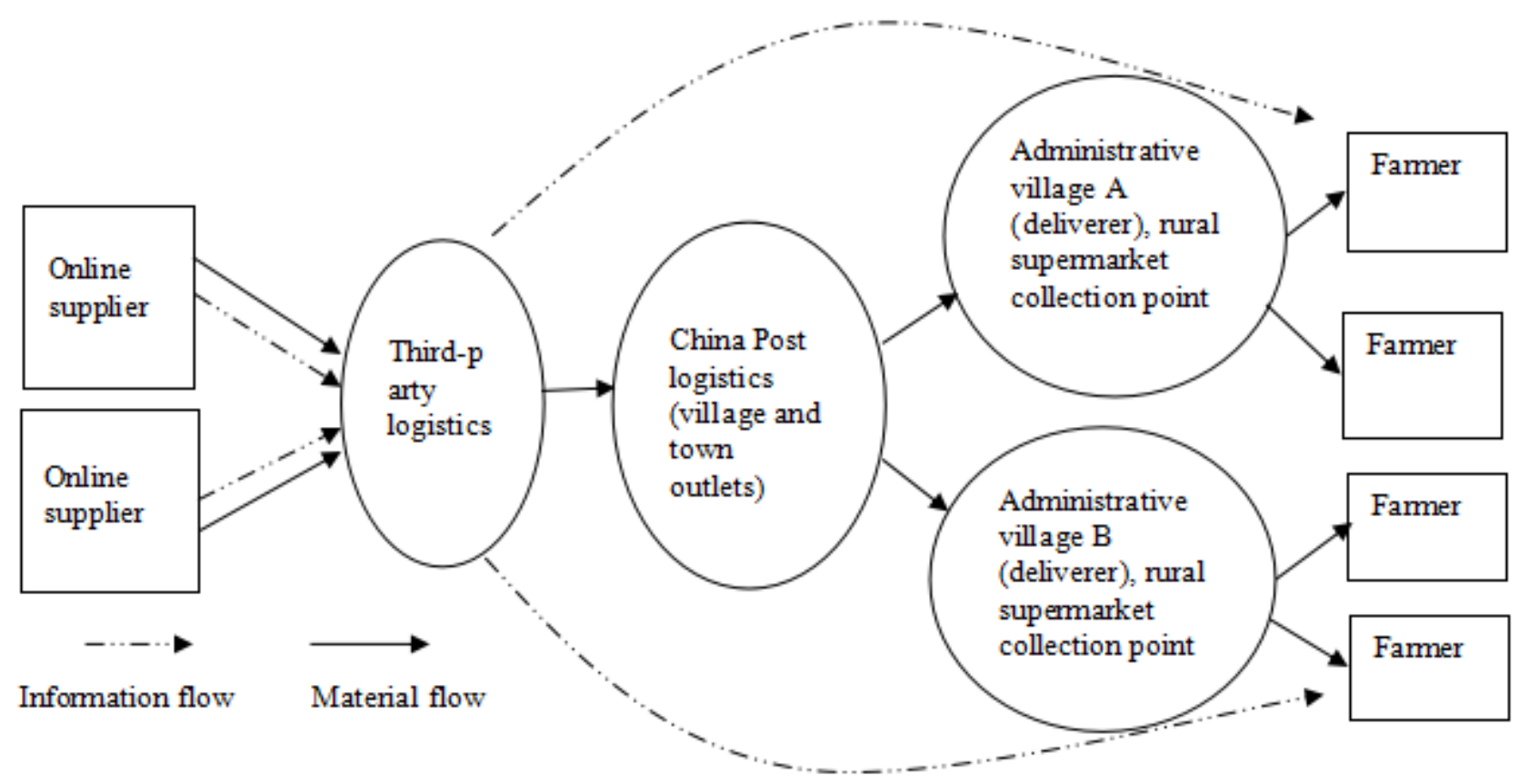

Fig.1 Circulation Mode of "Third-party Logistics + Postal Logistics" of Agricultural Materials and Rural Consumer Goods 
(2) Farm product circulation mode

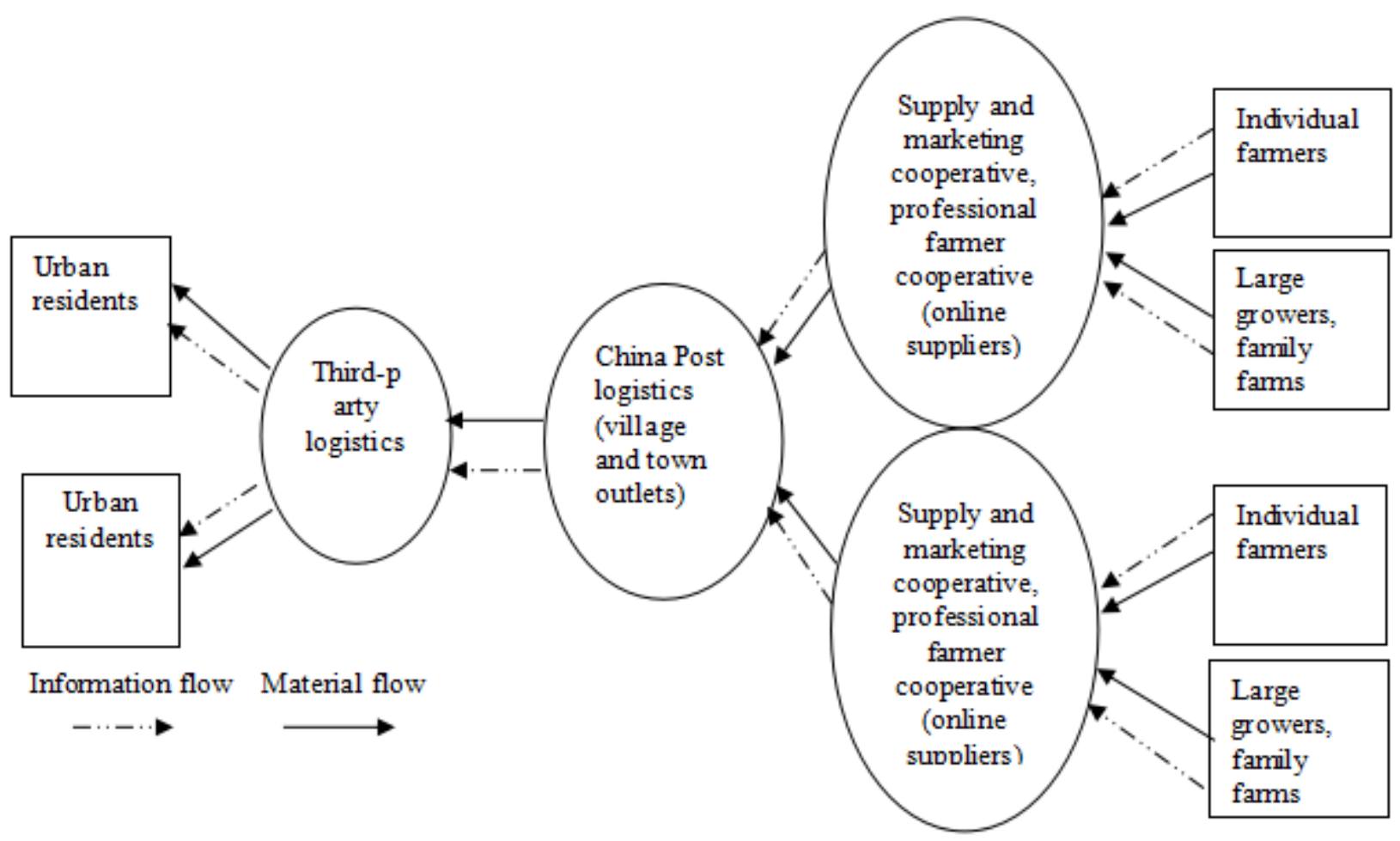

Fig.2 Farm Product Circulation Mode of "Third-party Logistics + Postal Logistics"

\subsubsection{Intensive operation mechanism of this mode}

On one hand, third-party logistics and postal logistics complement each other. Presently, only postal logistics possesses vast material distribution network and financial network across Chinese countryside after decades of operation and wins farmers' trust and support, so taking full advantage of postal logistics will greatly save costs for market development and shorten the process of rural logistics construction. However, postal logistics has long been dedicated to EMS and it is a challenging process to transport, store and distribute farm products, so it needs a good cooperation with third-party logistics enterprises that owns various transport vehicles which could meet requirements in temperature, humidity and a host of logistics professionals proficient in logistics theory and practice. This presents an excellent opportunity for large third-party logistics enterprises that have well-developed networks in cities but lack network and cost advantages in rural areas.

On the other hand, third-party logistics service providers cooperate with postal logistics to share out their work. Third-party logistics enterprises are responsible for the transportation of agricultural materials and consumer goods ordered by farmers to China Postal Express \& Logistics' outlets in villages and towns, and distribute farm products at village and town outlets so as to avoid empty transport vehicle during return trips and reduce combined cost; with computer and professional logistics staff in villages and towns, China Post uses rural logistics processing software and public network information platform to distribute goods to each administrative village or rural supermarket; meanwhile, China Post receives orders from supply and marketing cooperatives and farmers 'professional cooperatives (online suppliers) and transports them to third-party logistics; supply and marketing cooperatives and farmers 'professional cooperatives directly reach farmers and large growers, family farms and other new agricultural entities and engage in purchase, processing, packaging and sales of agricultural byproducts, which achieves an effective integration of physical sales and online sales. The two-way circulation mode of third-party enterprises and postal logistics has realized its "multifunctional role”. 


\subsection{The circulation mode of "farming-school, farming-supermarket, farming-enterprise"}

\subsubsection{Farm product circulation mode}

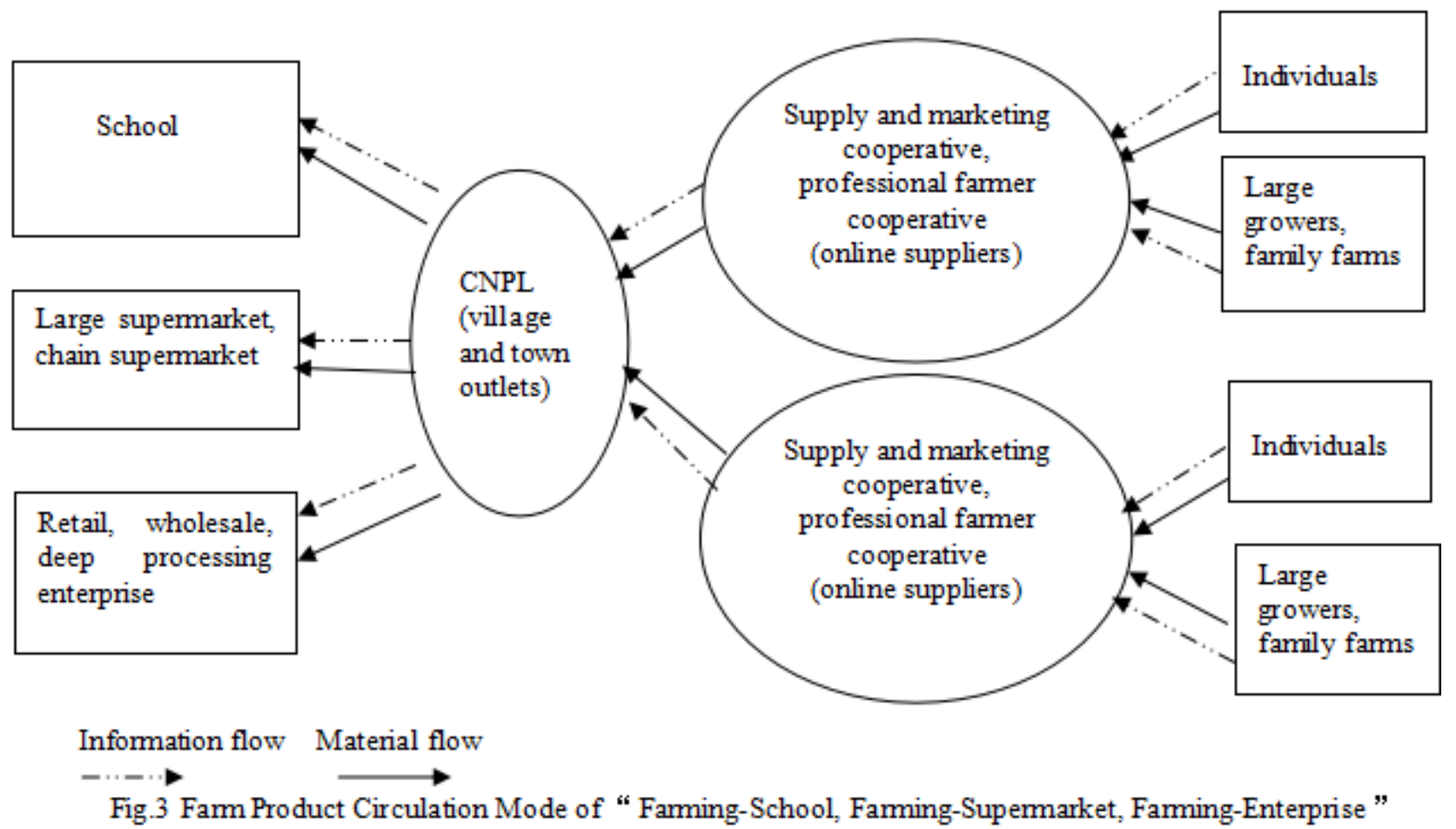

\subsubsection{Intensive operation mechanism of this mode}

On one hand, China Post Logistics(CNPL) establishes win-win cooperation with supply and marketing cooperatives and farmers 'professional cooperatives.

With large warehouses in many cities and towns, China Postal now has the highest coverage rate in China, which is incomparable for any third-party logistics service providers. And it is equipped with postal integrated computer network, postal physical network and postal financial network. It is not an exception for Hubei province. Currently, under the leadership of local governments in Hubei, an increasing number of third-tier and fourth-tier cities are expanding their market for EMS and strengthening the capability of postal enterprises to serve "agriculture, farmers and rural areas" , for example, China Post EMS Company has established logistics information platform for "Rural Integrated Logistics Service Station in Donggong, Nanzhang County" based on Nanzhang Outlet of Xiangyang Branch.

In Hubei, supply and marketing cooperative at all levels are playing the leading role in promoting the consumption of consumer goods in rural areas. Retail sales of supply and marketing cooperatives accounts for $45 \%$ of the total rural consumer goods sales in Hubei; meanwhile, the supply and marketing system has brought about a number of strong trade chain enterprises and brands. For instance, Hubei New Cooperation Joint-Stock Trade Chain Co., Ltd. is a key enterprise in the rural consumer goods circulation network of the supply and marketing system, and it has set up 7 regional subsidiaries, 8 distribution centers, 74 supermarkets, 1,392 franchised stores and 2,182 distribution service points, delivering annual turnover of RMB 300 million. With a growing number of rural chain supermarkets and stores of agricultural materials, supply and marketing cooperatives rely on village organizations to set up a lot of integrated rural service cooperatives.

On the other hand, China Post, supply and marketing cooperatives and farmers 'professional cooperatives do their share of work on a cooperative basis.

In the mode of "farming-supermarket, farming-school, farming-enterprise" , supply and marketing cooperatives and farmers 'professional cooperatives purchase farm products from farmers, large growers and family farms and transport them to CNPL's outlets in villages and towns ; 
meanwhile, as online suppliers, the cooperatives sign agreement of intent with farmers and supply quality farm products to supermarkets, schools, enterprises, stores and markets. Fundamentally, this mode is meant to introduce modern logistics to rural areas, connect farmers' production with changing market, build production-marketing chain in market economy environment, reduce farm product circulation process and cost and achieve intensive development.

\subsection{Two-way circulation mode of " the leading enterprises in the agricultural industrialization+ farmer"}

\subsubsection{Circulation mode}

(1) Farm product circulation mode

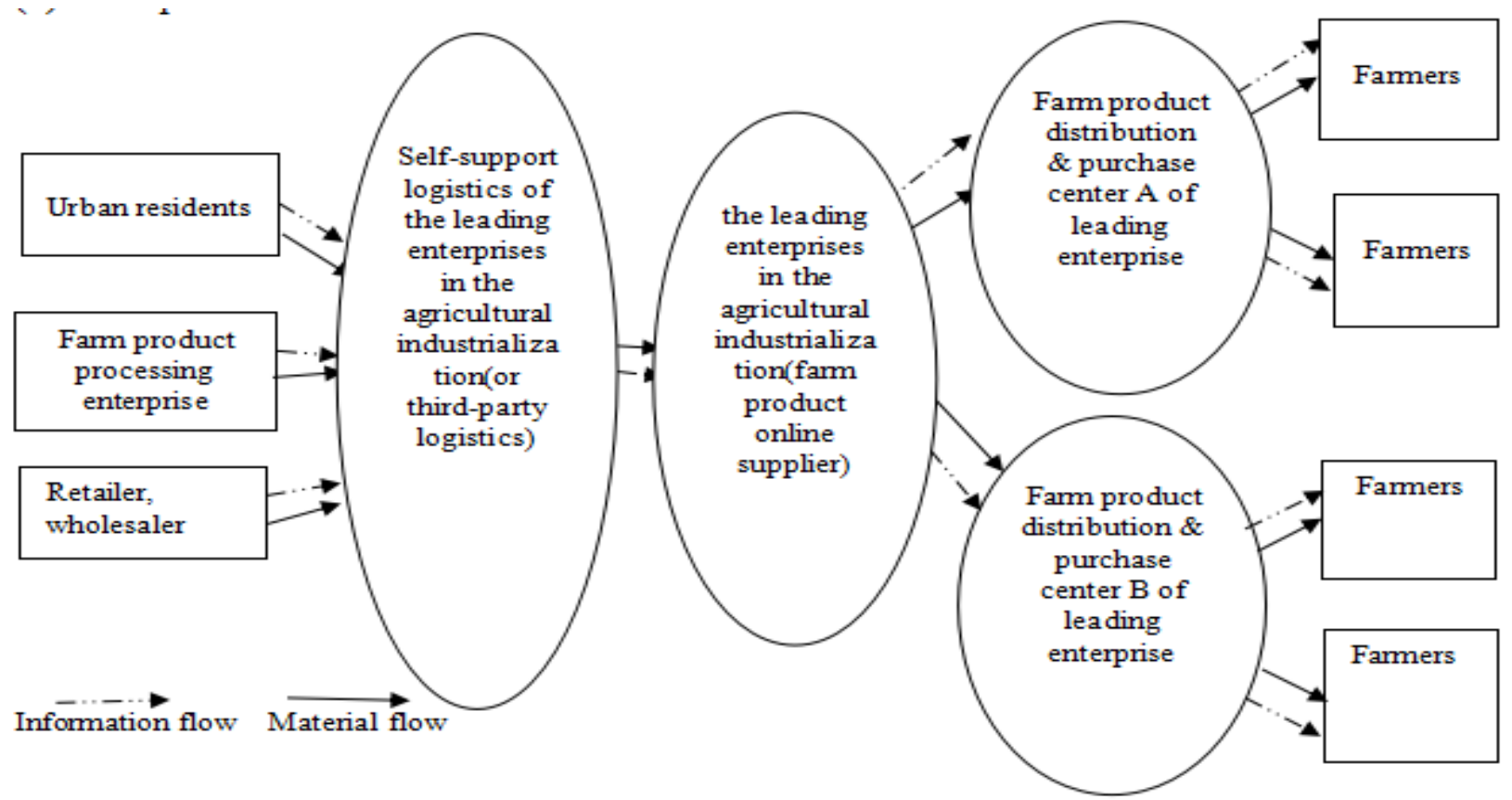

Fig.4 Farm Product Circulation Mode of "the leading enterprises in the agricultural industrialization+ Farmer" (2) Circulation mode of agricultural materials

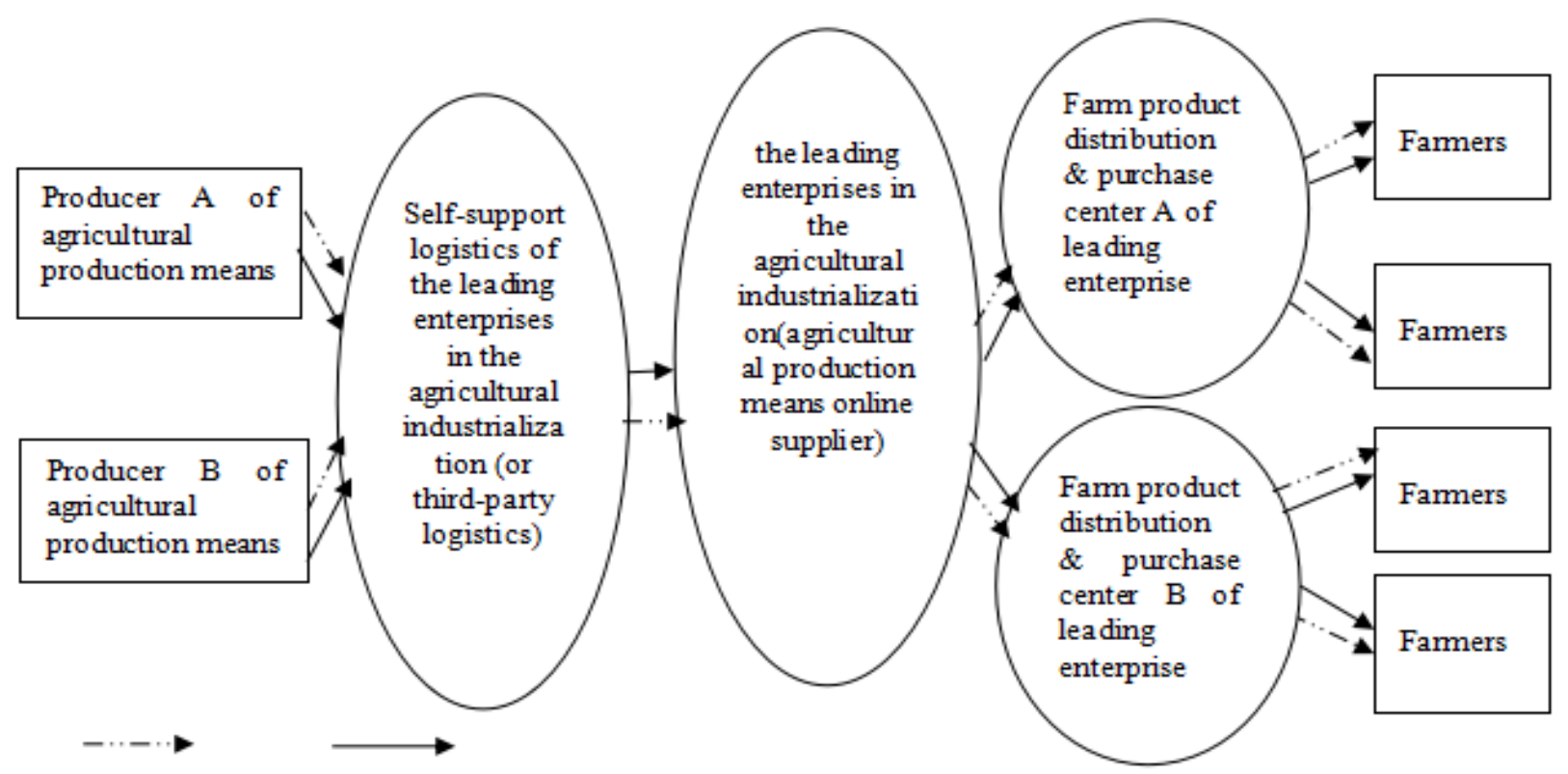

Information flow Material flow

Fig.5 Agricultural Materials Circulation Mode of "the leading enterprises in the agricultural industrialization+ Farmer" 


\subsubsection{Intensive operation mechanism of this mode}

As there are a vast number of the leading enterprises in the agricultural industrialization in Hubei, especially provincial-level key enterprises that can fully cover each village, county and city across Hubei province, this mode, led by provincial-level agribusiness key enterprises, can tap its advantages in the quantity, size and circulation capability and vigorously encourage those enterprises to extend their logistics service to reach every village. In this mode, the provincial-level agribusiness key enterprise is an online supplier and distributor of agricultural materials, which fully reflects the intensive concept of being “one point with multiple functions, one network with multiple purposes”.

\section{Conclusion}

The intensive development mode of rural logistics network in Hubei, which serves as a helping hand for Agricultural e-commerce, will accelerate the integration of "industry + agriculture" dual economy, facilitate urban-rural integration and solve the problems of "first-mile logistics" for farm products and "last-mile logistics" for industrial products. In this mode, we need to continue to explore how to better bring into play each node in rural logistics network.

\section{Acknowledgment}

This paper is one of the stage-based achievements of 2015 scientific research project titled Research on Intensive Development Mode of Rural Logistics Network in Hubei that Boosts Agricultural e-commerce by Agricultural e-commerce Hubei Provincial Collaborative Innovation Center (Cultivation), Wuhan Donghu College.

This paper is one of the stage-based achievements of 2014 Hubei Provincial Social Science Foundation Project titled A Study on the Coordinated Development of Agricultural E-commerce and Rural Logistics Network in Hubei (Project No.: 2014051).

\section{References}

[1]Duan Lijie, Research on the Creation of Farm Product Logistics of Hubei in the Context of e-commerce[J], Logistics Engineering and Management, Issue 10: 142-144, 2013.

[2]Wang Bing, Exploring the Mode of Agricultural e-commerce Platform in Hubei[J], Pioneering with Science \& Technology Monthly, Issue 10: 83-34, 2009.

[3]Hu Yunbin, Relationship Between Logistics and e-commerce[J]. Chinese \& Foreign Entrepreneurs, Issue 17: 106, 2013.

[4]Liu Chuanlong, Research on the Relationship Between e-commerce and Logistics[J], Management Observer, Issue 14: 77-78, 2013

[5]Bie Daoxue, Ma Haoying, Bai Jing, Collaborative Development of e-commerce and Modern Logistics[J], Logistics Technology, Issue 23:87-88+94, 2013.

[6] Luo Xingwu, The Creation of Urban-Rural Commodity Circulation Agricultural Logistics Mode from the Perspective of Low-carbon[J], Business Times, 2012, (3), 21-23. 